\title{
Correction to: Towards Household Asset Protection: Findings from an Inter-generational Asset Transfer Project in Rural Kenya
}

Njeri Kagotho ${ }^{1}$ (D)

Published online: 5 August 2019

(C) Springer Nature Switzerland AG 2019

\section{Correction to: Global Social Welfare} https://doi.org/10.1007/s40609-019-00160-5

The original version of this article unfortunately contained a mistake in the image of Fig. 1. Boxes of some texts in the said figure are missing. The corrected version of Fig. 1 is shown below.

The online version of the original article can be found at https://oi.org/ 10.1007/s40609-019-00160-5

Njeri Kagotho

kagotho.1@osu.edu

1 The Ohio State University College of Social Work, 325-E Stillman Hall, 1947 College Road, Columbus, OH 43210, USA 
Fig. 1 Inheritance action structural equation model

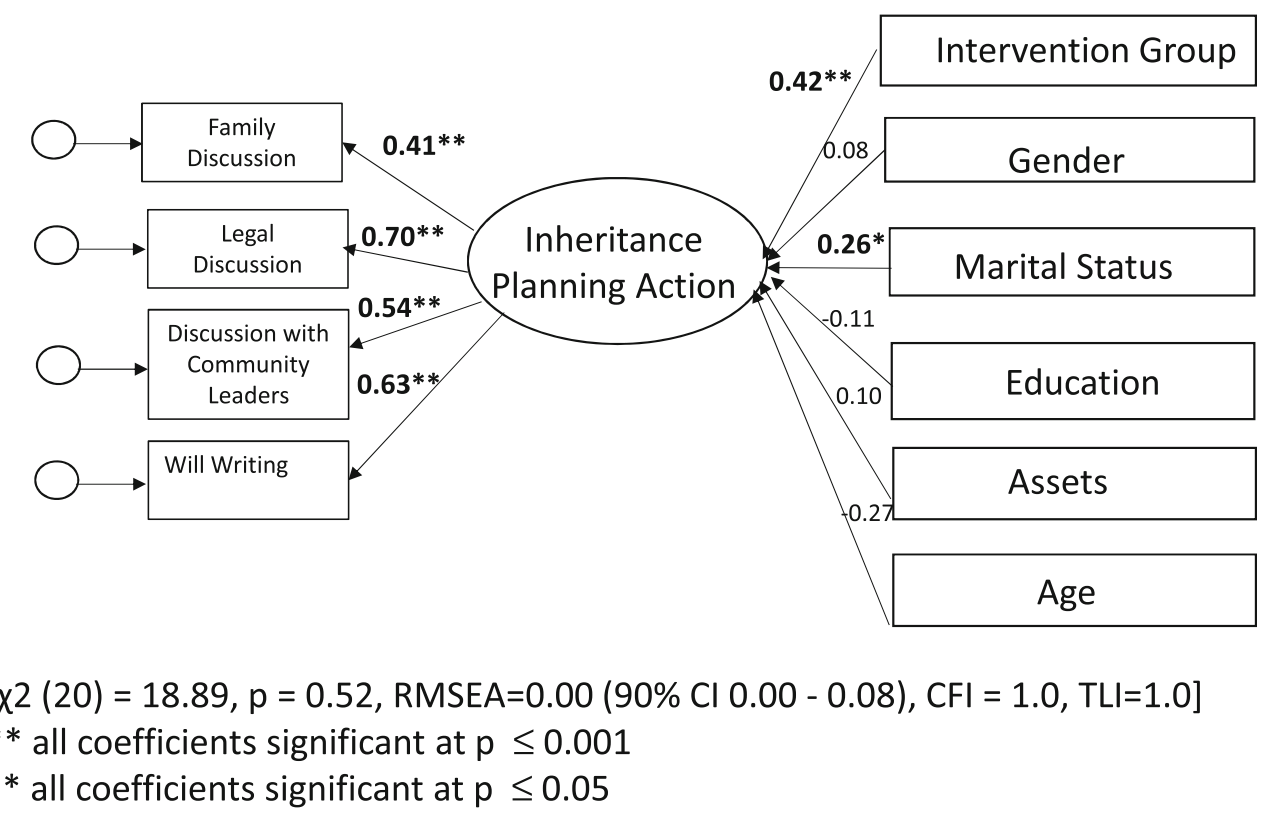

The original article has been corrected.

Publisher's Note Springer Nature remains neutral with regard to jurisdictional claims in published maps and institutional affiliations. 